\title{
Thermal Degradation Kinetics of iPP/Pd Nanocomposite Prepared by a Drying Process
}

\author{
Y Jae-Young Lee ${ }^{1}$, Hong-Ki Lee ${ }^{1}$, Sung-Wan Hong ${ }^{2}$, Il-Yub Choi ${ }^{3}$ \\ ${ }^{1}$ Hydrogen Fuel Cell Parts and Applied Technology RIC Woosuk Univ., Wanju, Korea \\ ${ }^{2}$ Dept. of Cosmetics, Woosuk Univ. Samnye, Korea \\ ${ }^{3}$ Dept. of Enviro. Eng., Univ. of Seoul, Seoul, Korea \\ Email: hongkil@woosuk.ac.kr
}

Received 2012

\begin{abstract}
Palladium (Pd) nanoparticles were incorporated into isotactic polypropylene (iPP) film by a one-step dry process. iPP film was exposed to the sublimed $\mathrm{Pd}(\mathrm{acac})_{2}$ vapor in a glass vessel at $180^{\circ} \mathrm{C}$. The Pd nanoparticles were observed by transmission electron microscope (TEM), and it was found that metallic nanoparticles were selectively loaded on the amorphous regions between the lamellae in iPP. Thermal degradation kinetics was investigated by introducing the data of thermogravimetric analysis (TGA) to Flynn \& Wall equation. TGA data showed that thermal degradation temperature $\left(\mathrm{T}_{\mathrm{d}}\right)$ of the neat iPP was improved about $35^{\circ} \mathrm{C}$ by loading $0.27 \mathrm{wt} \%$ Pd nanoparticles. Thermal degradation activation energy $\left(E_{d}\right)$ for iPP/Pd nanocomposite was $227.85 \mathrm{~kJ} / \mathrm{mol}$ while that of neat iPP was $220.57 \mathrm{~kJ} / \mathrm{mol}$. These results meant that the Pd nanoparticles acted as a retardant in the thermal degradation of neat iPP polymer chain.
\end{abstract}

Keywords: Pd Nanoparticles; Polymer Nanocomposite; Isotactic Polypropylene; Thermal Degradation; Flynn \& Wall Equation

\section{Introduction}

Uniformly dispersed metallic nanoparticles into a polymer matrix can offer new functional materials in the various applications such as catalysts, optics, senses, magnetics and electrics. Therefore many researchers have investigated to develop new methods for the preparation of polymer/metal nanocomposites avoiding their easy oxidation, contamination, and aggregation problems, and these methods are mainly classified into five: (1) a metallic precursor solution and a polymer solution are mixed in a reactor, and then the metallic precursor is reduced to the metallic nanoparticles during stirring, heating and evaporating the solvent [1-3]; (2) a metallic precursor is dissolved in a monomer and then is thermally reduced during the polymerization at high reaction temperature [4,5]; (3) a colloidal metallic nanoparticles pre-prepared by other methods are mixed with a polymer solution or monomer and then it was evaporated or polymerized [6,7]; (4) a metallic precursor is dissolved in a solvent and the solution impregnates into a polymer matrix, and then metallic nanoparticles are generated by treating with reduction agents or thermolysis [8,9]; and (5) sublimed metallic precursor molecules penetrate into a polymer matrix and are reduced to self-assembled metallic nanoparticles $[10,11]$. The methods $1 \sim 4$ are wet process, while the last method 5 is a dry process.

Crystalline polypropylenes have strong mechanical properties and their numerous and versatile applications can be easily achieved by wide range of PP homopolymers and copolymers and by easy processability. Therefore they are widely used as bumpers and dashboards in automobiles, OPP films, fibers for membranes, pipes, etc., and the crystallinity is one of the most important factors for the determination of the properties [12,
13]. The explanation of the crystal structure in PP is started by stereo-isomerism. When PP monomers are polymerized, all the neighboring methyl groups in the PP chain can have two stereo-isomeric positions. If all the methyl groups arrange on the same side of the zigzag plain, it is defined as isotactic polypropylene (iPP), and if they arrange alternatively, it is called as syndiotactic PP (sPP), and each has polymorphism of crystal structure resulting from various thermal and solvent conditions $[12,14]$.

It was reported that the onset temperature of the thermal degradation, Td of alkyl polymer chains was improved by the incorporation of very small amount of palladium (Pd) nanoparticles $[10,11]$. Especially the Td values for crystalline polymers were remarkably increased, that is, Td of syndiotactic polystyrene was improved about 50oC through the incorporation of 1.5 wt $\%$ of Pd nanoparticles. It was maybe due that the dry process, the above method 5 could incorporate metallic nanoparticles into the polymer films without the destruction of bulk shape and even without the change of crystallinity, because metallic nanoparticles were generated and positioned on the amorphous regions in sPS. However that of atatic polystyrene was improved only about $18^{\circ} \mathrm{C}$ by $1.68 \mathrm{wt} \%$ Pd nanoparticles, while that of nylon 6 even decreased about $52.8^{\circ} \mathrm{C}$ by $15.6 \mathrm{wt} \% \mathrm{Pd}$ nanoparticles.

In this study, Pd nanoparticles were incorporated into iPP via the above method 5 and the thermal degradation kinetics was studied by Flynn \& Wall equation $[15,16]$ as follows:

$$
E_{d}=\frac{-R}{0.457} \frac{d(\log \beta)}{d\left(T^{-1}\right)}
$$

where, $E_{d}$ was activation energy for the thermal degradation, $R$ was the universal gas constant, $8.314 \mathrm{~kJ} / \mathrm{mol}, \beta$ was heating rate, 
and $\mathrm{T}^{-1}$ was the inversion of the absolute temperature at a selected degradation fraction, $\alpha . E_{d}$ values could be calculated from the linear relationships between $\log \beta$ and $\mathrm{T}^{-1}$ at each selected degradation fraction, $\alpha$, which was obtained from the dynamic thermogravimetric analysis (TGA) curves at various heating rates.

\section{Experimental}

\subsection{Materials}

Palladium(II) bis(acetylacetonate), $\operatorname{Pd}(\mathrm{acac})_{2}$ was purchased from Johnson Matthey Materials Technology, which was recrystallized in acetone prior to its usage. iPP was obtained from Chisso Ltd. (Japan) whose molecular weight, Mn was 224,000 and polydispersity index, Mw/Mn was 2.5. The iPP pellets were processed into a film with the thickness of $100 \mu \mathrm{m}$ by press molding and the humidity was removed in vacuum oven for $24 \mathrm{hr}$ at $40^{\circ} \mathrm{C}$.

\subsection{Incorporation of Pd Nanoparticles into iPP Film}

$2 \mathrm{mg}$ of $\mathrm{Pd}(\mathrm{acac})_{2}$ was weighed in a glass vessel $(30 \mathrm{ml})$ and the iPP film was positioned uprightly in the vessel as shown in Figure 1. Then air in the vessel was exchanged by nitrogen three times to prevent the formation of palladium oxide and the vessel was dipped into $180^{\circ} \mathrm{C}$ oil bath in vacuo in order to expose the $\mathrm{Pd}(\mathrm{acac})_{2}$ vapor to the iPP film uniformly for $0,30,60$ and $120 \mathrm{~min}$, respectively. Finally, the penetrated vapor was reduced to Pd nanoparticles during the same step without any additional treatment.

\subsection{TEM Observation}

Transmission electron microscopy (TEM) was employed with a LEO922 energy-filtering transmission electron microscope (Carl Zeiss Co. Ltd., Germany) at an accelerating voltage of $200 \mathrm{kV}$. Thin section was prepared by cryo-ultramicrotomy at $-60^{\circ} \mathrm{C}$ after embedding in a light curable resin system (D-800, JEOL DATUM, Japan). The average diameter of Pd nanoparticles and its number density displayed on TEM image were statistically estimated by the image processing software (analySIS, Soft Imaging System Co. Ltd.).

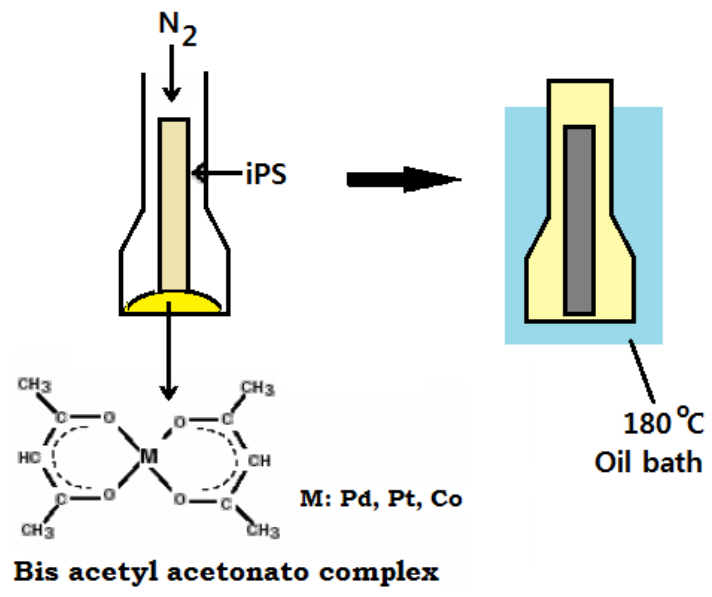

Figure 1. One-step dry process.

\subsection{TG Analysis}

To study the thermal degradation kinetics, thermogravimetric analysis (TGA) was employed using a thermal analysis system (TG/DTA 6200, EXTRA 6000 series, Seiko Instruments Inc., Japan). The analysis was carried out at a $\mathrm{N}_{2}$ flow rate of 200 $\mathrm{ml} / \mathrm{min}$ to prevent the oxidation of the composites. $5 \mathrm{mg}$ film chip was used as sample and dynamic run was carried out from room temperature to $600^{\circ} \mathrm{C}$ at heating rates of $5,10,15$ and 20 ${ }^{\circ} \mathrm{C} / \mathrm{min}$. The sensitivity of the TGA apparatus is $0.2 \mathrm{mg}$, and thus the minimum content to be measured was $0.004 \mathrm{wt} \%$ of a $5 \mathrm{mg}$ sample.

\section{Results and Discussion}

Figure 2(A) showed TEM micrograph of a cross section of iPP film incorporated with Pd nanoparticles which was prepared by the exposure to $\mathrm{Pd}(\mathrm{acac})_{2}$ vapor for $30 \mathrm{~min}$ and the TEM image (B) was obtained from the same specimen except only staining with $\mathrm{RuO}_{4}$. In the image (A), very few of Pd nanoparticles were generated and some of them formed aggregations containing 2 4 nanoparticles, even over 10 particles was shown in the inset of the image (A). The average diameter of the individual nanoparticles was $7.5 \mathrm{~nm}$ with a standard deviation of $1.8 \mathrm{~nm}$. The staining with $\mathrm{RuO}_{4}$ was helpful tool to observe the lamellar morphologies in a crystalline polymer because it was selectively stained on the amorphous regions which were formed by tie molecules jointing the lamellae. As shown in Figure 2(B), Pd nanoparticles expressed as black dots selectively positioned on the amorphous regions expressed as black lines, and the inset of the image (B) showed the aggregated area with 9 nanoparticles where it was stained more darkly. It meant that the area with many nanoparticles had large defect point in the crystal structure so that many $\mathrm{RuO}_{4}$ compounds could stain that area.
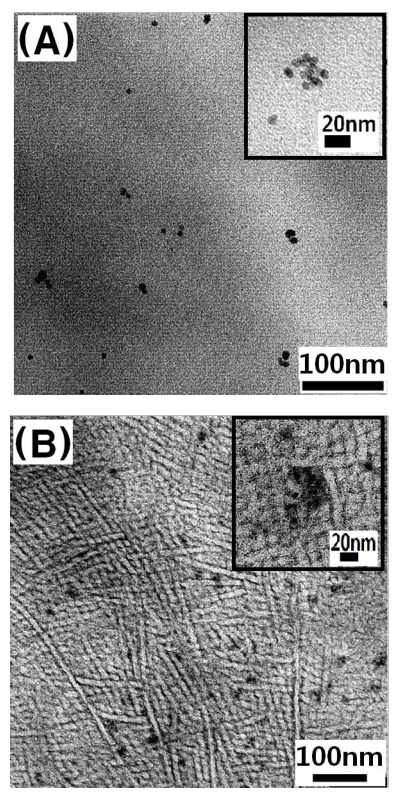

Figure 2. TEM micrographs of cross sections of iPP/Pd nanocomposite films prepared by the exposure to $\mathrm{Pd}(\mathrm{acac})_{2}$ vapor for $30 \mathrm{~min}$. (A) was the image of unstained specimen, while $(B)$ is the image of stained specimen with $\mathrm{RuO}_{4}$. The insets showed the aggregation consisted of over 10 nanoparticles. 
Figure 3 showed the dynamic TGA and DTG curves for iPP/ Pd nanocomposites with various amounts of the Pd nanoparticles. The heating rate was at $10{ }^{\circ} \mathrm{C} / \mathrm{min}$ in nitrogen atmosphere. It was clearly shown that the incorporation of the Pd nanoparticles shifted the TGA curves to higher temperature. It implied that the thermal stability was remarkably improved by the incorporation of Pd nanoparticles. In the TG curve of neat iPP, there was almost no weight loss before $372^{\circ} \mathrm{C}$ and it decreased very slowly until $404^{\circ} \mathrm{C}$, but it was very quickly decreased after that temperature and almost all polymer chains were degraded abruptly between $404 \sim 482^{\circ} \mathrm{C}$. However, the TGA curve of the iPP/Pd nanocomposite prepared by the exposure to $\mathrm{Pd}(\mathrm{acac})_{2}$ vapor for $30 \mathrm{~min}$ was very different from that of neat iPP. It showed no weight loss before $409^{\circ} \mathrm{C}$, slow decrement until $439^{\circ} \mathrm{C}$, and abrupt degradation between $439 \sim 483^{\circ} \mathrm{C}$, where the $\mathrm{Pd}$ incorporation weight of the sample was $0.27 \mathrm{wt} \%$. It was an amazing result that the thermal stability of the neat iPP was improved by $35^{\circ} \mathrm{C}$ via the incorporation of such very small amount of the Pd nanoparticles. In here, the incorporation weight of Pd nanoparticles was obtained from the prolysis at $1,000^{\circ} \mathrm{C}$ nitrogen atmosphere in an electric furnace for $3 \mathrm{hr}$. In the DTG curves, compared to that of iPP/Pd nanocomposite, the steeper slope in the former part and the similar slope in the latter part of the neat iPP maybe said that the Pd nanoparticles mainly contributed to the improvement in the initial degradation of neat iPP, and it was maybe due that nanoparticles positioned on the defects of crystal structure held the polymer chains tightly until higher temperature. Figure $\mathbf{3}$ also showed that the increasing Pd content from $0.27 \mathrm{wt} \%$ to $0.57 \mathrm{wt} \%$ could not bring the better results as was expected.

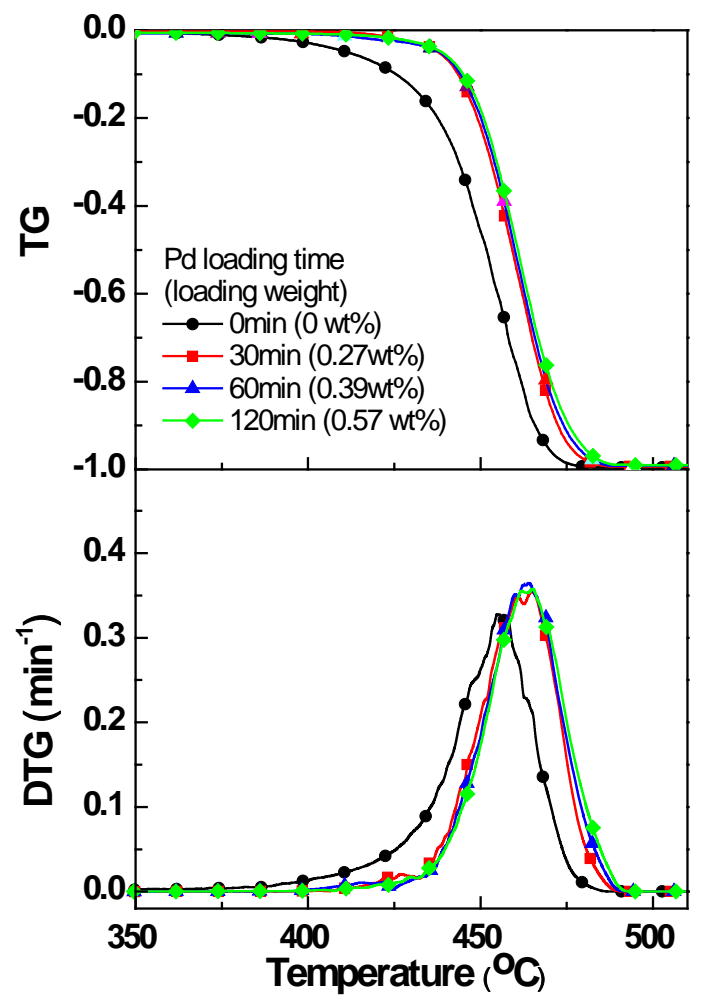

Figure 3. TGA and DTG curves for iPP/Pd nanocomposites prepared at different $\mathrm{Pd}(\mathrm{acac})_{2}$ exposure time.
In order to estimate the thermal degradation rate, the TGA data at various heating rates were introduced to Flynn \& Wall equation. Figure 4 showed the TGA curves for the iPP/Pd $(0.27 \mathrm{wt} \%)$ nanocomposite at the heating rates of $5,10,15$ and $20{ }^{\circ} \mathrm{C} / \mathrm{min}$. The temperature values at $\alpha=0.05$ for each heating rate were $428.30,438.16,447.26$, and $452.95^{\circ} \mathrm{C}$, respectively. To get $E_{d}$ value at each $\alpha$, these values were converted to $T^{-1}$ and introduced to the Flynn \& Wall equation together with $\log \beta$ listed in Table 1. Using the same procedure, the temperatures at different $\alpha$ for each heating rate were obtained from Figure 4, and the $\mathrm{T}^{-1}$ values were also listed in Table 1 . Then a straight line for each $\alpha$ was plotted by the relationship between $\log \beta$ and $\mathrm{T}^{-1}$ data for Flynn \& Wall equation, as displayed in Figure 5. The linear correlation for $\alpha=0.05$ was expressed as $\log \beta=$ $-12.25 \times 10^{3} \cdot \mathrm{T}^{-1}+18.19$. So, the $\mathrm{E}_{\mathrm{d}}$ value was calculated from the slope, $-12.25 \times 10^{3}=-0.457 \cdot E_{d} / R$, so that the $E_{d}$ value at $\alpha=$ 0.05 was $222.86 \mathrm{~kJ} / \mathrm{mol}$. The $E_{\mathrm{d}}$ values for various $\alpha$ were also obtained through the same procedure and shown in Figure 6. The average $E_{d}$ value for iPP/Pd (0.27 wt\%) nanocomposite was $227.85 \mathrm{~kJ} / \mathrm{mol}$, which was very similar value, $228 \mathrm{~kJ} / \mathrm{mol}$ calculated from Kissinger equation [11]. The $E_{d}$ value for neat iPP was also calculated by the same procedure and we obtained the average value of $220.57 \mathrm{~kJ} / \mathrm{mol}$, which was also displayed in Figure 6 and was $7.28 \mathrm{~kJ} / \mathrm{mol}$ lower. These results meant that the Pd nanoparticles could act as a retardant in the thermal degradation of neat iPP polymer chain.

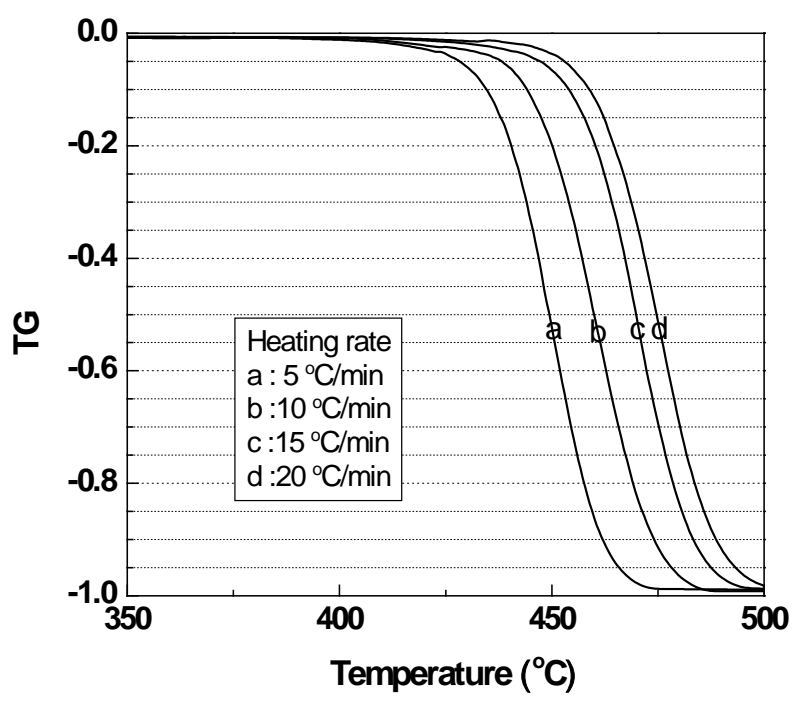

Figure 4. TGA curves for iPP/Pd (0.27 wt \%) nanocomposite at different heating rates.

Table 1. Relationships between $\log \beta$ and $\mathrm{T}^{-1}$ for the iPP/Pd $(0.27$ wt\%) Nanocomposite.

\begin{tabular}{|c|c|c|c|c|c|c|c|c|c|c|}
\hline \multirow{2}{*}{$\log \beta$} & \multicolumn{4}{|l|}{$\alpha$} & \multicolumn{5}{|c|}{$\mathrm{T}^{-1} \times 10^{3}\left(\mathrm{~K}^{-1}\right)$} & \multirow[b]{2}{*}{0.50} \\
\hline & 0.05 & 0.10 & 0.15 & 0.20 & 0.25 & 0.30 & 0.35 & 0.40 & 0.45 & \\
\hline 0.70 & 1.425 & 1.413 & 1.406 & 1.398 & 1.397 & 1.394 & 1.391 & 1.388 & 1.387 & 1.384 \\
\hline 1.00 & 1.406 & 1.394 & 1.388 & 1.379 & 1.378 & 1.375 & 1.372 & 1.369 & 1.366 & 1.364 \\
\hline 1.18 & 1.388 & 1.375 & 1.368 & 1.340 & 1.359 & 1.356 & 1.353 & 1.351 & 1.348 & 1.346 \\
\hline 1.30 & 1.377 & 1.366 & 1.360 & 1.352 & 1.351 & 1.348 & 1.345 & 1.342 & 1.340 & 1.337 \\
\hline
\end{tabular}




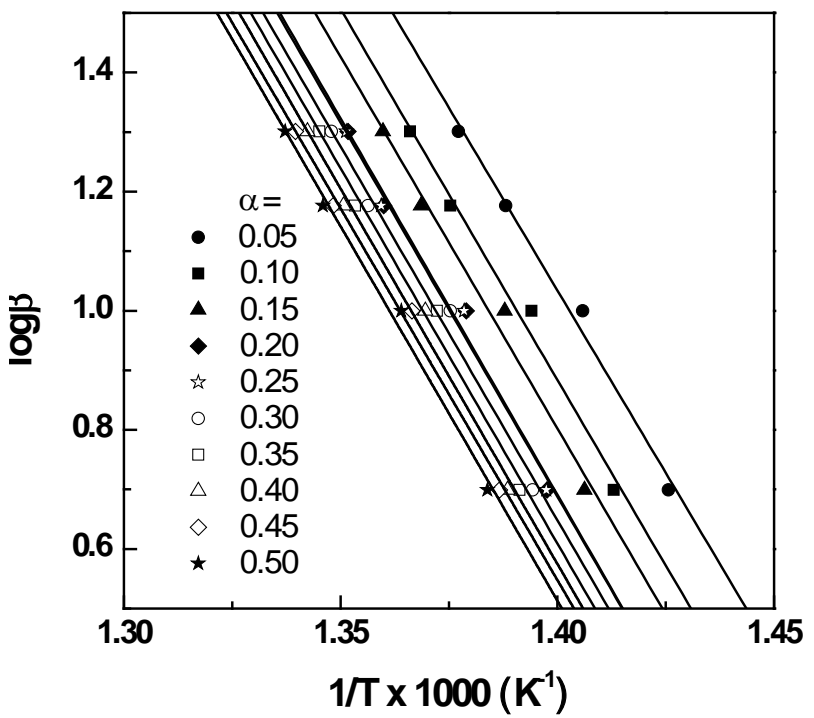

Figure 5. Isoconversional plots of $\log \beta$ vs.1/T for iPP/Pd (0.27 wt \%) nanocomposite.

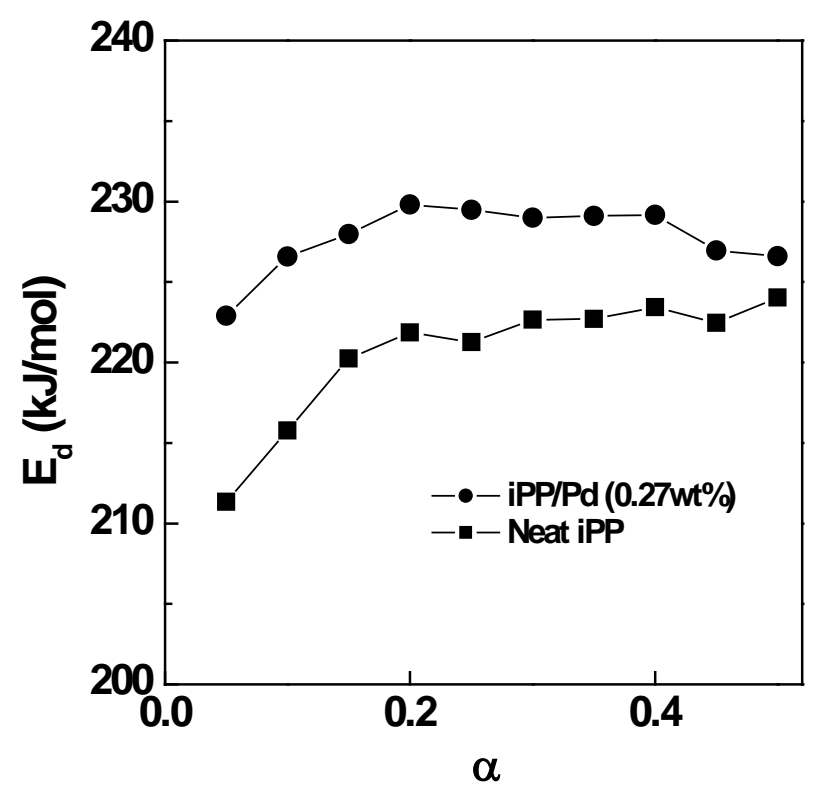

Figure 6. $E_{d}$ value tendency of neat iPP and iPP/Pd (0.27 wt\%) nanocomposite according to increasing degradation fraction, $\alpha$.

\section{Conclusion}

iPP/Pd nanocomposites were prepared by the incorporation of $\mathrm{Pd}(\mathrm{acac})_{2}$ vapor into free-standing iPP film in one-step dry process and thermal degradation kinetics was investigated by TGA and Flynn \& Wall equation. TEM observation showed that very few Pd nanoparticles was generated selectively on the amorphous regions in the crystalline iPP and 0.27 wt\% Pd nanoparticle was incorporated into iPP film through the exposure to $\mathrm{Pd}(\mathrm{acac})_{2}$ vapor for $30 \mathrm{~min}$. However, such a very low content of Pd nanoparticles have positive effect on the thermal degradation of the neat iPP, that is $0.27 \mathrm{wt} \% \mathrm{Pd}$ nanoparticles improved the thermal degradation temperature by $35^{\circ} \mathrm{C}$. $\mathrm{E}_{\mathrm{d}}$ value for iPP/Pd (0.27 wt\%) nanocomposite was
$227.85 \mathrm{~kJ} / \mathrm{mol}$ while that of neat iPP was $220.57 \mathrm{~kJ} / \mathrm{mol}$. However the increasing Pd content from $0.27 \mathrm{wt} \%$ to $0.57 \mathrm{wt} \%$ could not bring any improvement in thermal degradation.

\section{Acknowledgements}

This work was supported by the Program of Regional Innovation Center which was conducted by the Ministry of Knowledge Economy of the Korean Government. This work was also supported by Woosuk University (2012).

\section{REFERENCES}

[1] M. M. Demir, M. A. Gulgun, Y. Z. Menceloglu, B. Erman, S. S. Abramchuk, and E. E. Makhaeva, "Palladium nanoparticles by electrospinning from poly(acrylonitrile-co-acrylic acid)- $\mathrm{PdCl}_{2}$ solutions. Relations between preparation conditions, particle size, and catalytic activity," Macromolecules, vol. 37, pp. 1787-1792, 2004.

[2] D. S. dos Santos Jr., P. J. G. Goulet, N. P. W. Pieczonka, O. N. Oliveira Jr., and R. F. Aroca, "Gold nanoparticle embedded, self-sustained chitosan films as substrates for surface-enhanced Raman scattering," Langmuir, vol. 20, pp. 10273-10277, 2004.

[3] S. Porel, S. Singh, S. S. Harcha, D. N. Rao, and T. P. Radhakrishnan, "Nanoparticle-embedded polymer: In situ synthesis, free-standing films with highly monodisperse silver nanoparticles and optical limiting," Chem. Mater., vol. 17, pp. 9-12. 2005.

[4] C. Lu, C. Guan, Y. Liu, Y. Cheng, and B. Yang, "PbS/Polymer nanocomposite optical materials with high refractive index," Chem. Mater., vol. 17. pp. 2448-2454, 2005.

[5] A. J. Haes, S. Zou, G. C. Schatz, and R. P. Van Duyne, "Nanoscale optical biosensor: short range distance dependence of the localized surface plasmon resonance of noble metal nanoparticles," J. Phys. Chem. B, vol. 108, pp. 6961-6968, 2004.

[6] Z. H. Mibhele, M. G. Salemane, C. G. C. E. van Sittert, J. M. Nedeljković, V. Djoković, and A. S. Luyt, "Fabrication and characterization of silver-polyvinyl alcohol nanocomposites," Chem. Mater., vol. 15, pp. 5019-5025, 2003.

[7] K. J. Klabunde, J. Habdas, and T. G. Cardenas, "Colloidal metal particles dispersed in monomeric and polymeric styrene and methyl methacrylate," Chem. Mater., vol. 1, pp. 481-483, 1989.

[8] S. G. Boyes, B. Akgun, W. J. Brittain, and M. D. Foster, "Synthesis, Characterization and properties of polyelectrolyte block copolymer brushes prepared by atom transfer radical polymerization and their use in the synthesis of metal nanoparticles," Macromolecules, vol. 36, pp. 9539-9548, 2003.

[9] S. Yoda, A. Hasegawa, H. Suda, Y. Uchimaru, K. Haraya, and T. Tsuji, "Preparation of platinum and palladium/polyimide nanocomposite film as a precursor of metal doped carbon molecular sieve membrane via supercritical impregnation," Chem. Mater., vol. 16, pp. 2363-2368, 2004.

[10] J. Y. Lee, S. Horiuchi, and H. K Choi, "Effect of palladium nanoparticles on the thermal degradation kinetics of $\alpha$ crystalline syndiotactic polystyrene," J. Ind. Eng. Chem., vol. 12, pp. 862-867, 2006.

[11] J. Y. Lee, Y. G. Liao, R. Nagahata, and S. Horiuchi, "Effect of metal nanoparticles on thermal stabilization of polymer/metal nanocomposites prepared by a one-step dry process," Polymer, vol. 47, pp. 7970-7979, 2006.

[12] J. Varga, "Polypropylene: structure andmorphology," ed. by J. Karger-Kocsis, Chapman \& Hall, London, 1995.

[13] J. Junkasem, J. Menges, and P. Supaphol, "Mechanical properties 
of injection-molded isotactic polypropylene/roselle fiber composites," J. Appl. Polym. Sci., vol. 101, pp. 3291-3300, 2006.

[14] X. Sun, H. Li, J. Wang, and S. Yan, "Shear-induced interfacial structure of isotactic polypropylene (iPP) in iPP/fiber composites," Macromolecules, vol. 39, pp. 8720-8726, 2006.

[15] J. H. Flynn, "Degradation kinetics applied to lifetime predictions of polymers," Polym. Eng. Sci., vol. 20, pp. 675-677, 1980.

[16] J. Y. Lee, H. K. Lee, M. J. Shim, and S. W. Kim, "Thermal decomposition Characteristics of epoxy network chemically toughened with liquid rubber using dynamic TG analysis," J. Ind. Eng. Chem., vol. 6, pp. 250-255, 2000. 